\title{
Desempenho de cultivares de batata doce na região do Alto Paranaíba-MG
}

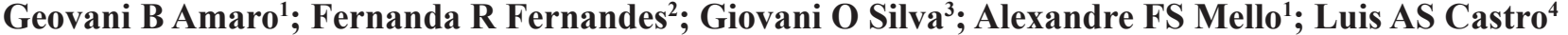 \\ 'Embrapa Hortaliças, Brasília-DF, Brasil; geovani.amaro@embrapa.br; alexandre.mello@embrapa.br; ${ }^{2}$ Embrapa Quarentena Vegetal, \\ Brasília-DF, Brasil; fernanda.rausch@embrapa.br; ${ }^{3}$ Embrapa Hortaliças-SPM, Canoinhas-SC, Brasil; giovani.olegario@embrapa.br; \\ ${ }^{4}$ Embrapa Clima Temperado, Pelotas-RS, Brasil; luis.suita@embrapa.br
}

\section{RESUMO}

A batata doce (Ipomoea batatas) é uma das principais hortaliças cultivada no Brasil. O objetivo do trabalho foi avaliar o desempenho agronômico das cultivares de batata doce da Embrapa na região do Alto Paranaíba-MG. Os experimentos foram conduzidos em condições de campo em lavouras comerciais, nos períodos de 12 de dezembro de 2012 a 14 de maio de 2013 e 11 de dezembro de 2013 a 13 de maio de 2014. Os dois experimentos foram instalados no delineamento em blocos ao acaso com quatro repetições para avaliar oito cultivares (BRS Amélia, Beauregard, Brazlândia Branca, Brazlândia Rosada, Brazlândia Roxa, BRS Cuia, Princesa e BRS Rubissol). Não houve diferença entre as cultivares avaliadas para os caracteres massa total de raízes, massa média de raízes comerciais e formato de raiz e, para esses caracteres as cultivares apresentaram desempenho semelhante nas duas safras de cultivo. Porém, as cultivares Brazlândia Roxa, Brazlândia Branca e Beauregard destacaram-se em relação às demais, e para a principal característica relacionada ao desempenho que é a massa de raízes com padrão comercial, com produtividades de 24,62, 21,25 e 20,69t/ha, para as três cultivares respectivamente, em 2013. As cultivares Brazlândia Roxa e Beauregard também apresentaram formato de raiz adequado e resistência a insetos, com destaque para a Brazlândia Roxa com nota 1,5 nos dois anos de avaliação. Desta forma, pode-se concluir que, dentre as cultivares avaliadas, a Beauregard é uma boa opção para os produtores do Alto Paranaíba-MG, mas a cultivar Brazlândia Roxa, que possui características qualitativas das raízes desejáveis ao mercado local com formato alongado, polpa creme e casca roxa, é a mais indicada para esta região.

Palavras-chave: Ipomoea batatas, produtividade, cultivares.

\section{ABSTRACT \\ Performance of sweet potato cultivars in the Alto Paranaíba region}

The sweet potato (Ipomoea batatas) is one of the main vegetables grown in Brazil. The aim of this work was to evaluate the agronomic performance of Embrapa sweet potato cultivars in the region of Paranaíba, Minas Gerais State, Brazil. The experiments were carried out under field conditions in commercial crops from December 12, 2012 to May 14, 2013 and December 11, 2013 to May 13, 2014. Two experiments were carried out in randomized blocks design with four replications to evaluate eight cultivars (BRS Amelia, Beauregard, Brazlândia Branca, Brazlândia Rosada, Brazlândia Roxa, BRS Cuia, Princesa and BRS Rubissol). Characters related to root dry mass production are highly influenced by the environment, as observed by the ranges of the coefficient of variation from $9.23 \%$ of commercial roots mass in relation to total root dry mass and $29.25 \%$ to total root mass. No significant differences among cultivars were found for total root mass, average commercial root mass and root shape. The cultivars performed equally well in the two crops. Nevertheless, Brazlândia Roxa, Brazlândia Branca and Beauregard out yielded the rest of the cultivars in 2013, achieving 24.62, 21.25 and $20.69 \mathrm{t} / \mathrm{ha}$ respectively. Brazlândia Roxa and Beauregard also showed adequate indexes of root shape and resistance to insects, especially Brazlândia Roxa with a 1.5 score in the two years of evaluation. Among the evaluated cultivars, Beauregard is a good option to the producers of Alto Paranaíba, but the Brazlândia Roxa cultivar, presenting root characteristics that are desirable to the local market preferences with elongated shape, pulp color and purple skin, is the most suited to this region.

Keywords: Ipomoea batatas, yield, cultivars.

\section{(Recebido para publicação em 16 de novembro de 2015; aceito em 20 de setembro de 2016)} (Received on November 16, 2015; accepted on September 20, 2016)

\begin{abstract}
$\mathrm{A}^{\mathrm{b}}$ batata doce (Ipomoea batatas) é uma das principais hortaliças cultivada no Brasil e em 2012 foram produzidas 479,4 mil toneladas, em 40.120 ha o que proporcionou uma produtividade de 11,9 t/ha (IBGE, 2014). O Triângulo Mineiro e Alto Paranaíba em Minas Gerais são tradicionais produtores de batata doce, com 12,2 mil toneladas de raízes em 2012, o que corresponde
\end{abstract}

a 2,5\% da produção nacional, em uma área plantada de 669 ha (IBGE, 2014). A importância econômica e social dessa cultura é resultante da rusticidade, ampla adaptação climática e elevada capacidade de produção de energia em curto espaço de tempo. Observou-se considerável diversidade genética entre cultivares e variedades locais de batata doce das diversas regiões produtoras do Brasil (Ritschel \& Huamán, 2002). Assim, diferentes genótipos são cultivados, porém são utilizados sem uma prévia avaliação e sem recomendação para uma determinada região.

A produtividade média nacional de batata doce é baixa. Com a utilização de manejo adequado pode-se atingir a produtividade de 25 a 30 t/ha em quatro a cinco meses de cultivo (Andrade 
Júnior et al., 2009, 2012; Amaro et al., 2014). No Brasil, um total de 27 cultivares de batata doce foram registradas no Ministério da Agricultura, Pecuária e Abastecimento (MAPA, 2014), mas o cultivo de variedades locais e não melhoradas é predominante, sendo um dos principais motivos pela baixa produtividade. Outro fato que pode estar associado à baixa produtividade é que a cultura é propagada vegetativamente, principalmente por meio de ramas. $\mathrm{O}$ uso contínuo de um mesmo material para cultivo e propagação pode levar ao acúmulo sistêmico de doenças e degeneração do material, especialmente pelas viroses (Fernandes, 2013). Além disso, pode-se considerar o nível de tecnologia aquém do desejável, aplicado à cultura pela maioria dos produtores. Portanto, para melhorar esta condição, além do manejo correto a campo e utilização de mudas sadias, faz-se necessário a adoção de cultivares mais produtivas, com formato de raízes comercialmente aceitável e resistência aos insetos de solo que danificam as raízes (Azevedo et al., 2014; Massaroto et al., 2014). O processo de limpeza clonal propicia à cultura da batata doce e outras também propagadas vegetativamente, a recuperação da degenerescência causada pelo acúmulo de fitopatógenos, especialmente os de etiologia viral, estabelecidos na cultura ao longo dos ciclos consecutivos. A técnica viabiliza a produção de grande número de plantas matrizes com elevada qualidade fitossanitária, homogeneidade, maior vigor, maior desempenho agronômico e elevada taxa de multiplicação (Fernandes, 2013).

Neste contexto, o objetivo do presente trabalho foi avaliar cultivares de batata doce utilizando mudas oriundas do processo de limpeza clonal, quanto ao rendimento de raízes, formato de raiz e resistência a danos por insetos.

\section{MATERIAL E MÉTODOS}

Os experimentos foram conduzidos na região do Alto Paranaíba, no estado de Minas Gerais, em condições de campo em lavouras comerciais, nos períodos de 12 de dezembro de 2012 a 14 de maio de 2013, em Guimarânia (1850’38”S, $46^{\circ} 47^{\prime} 35^{\prime \prime}$ ) e e 11 de dezembro de 2013 a 13 de maio de 2014 em Cruzeiro da Fortaleza (18 $\left.56^{\prime} 45^{\prime \prime} \mathrm{S}, 46^{\circ} 40^{\prime} 25^{\prime \prime} \mathrm{O}\right)$. Utilizou-se o delineamento de blocos ao acaso com quatro repetições para avaliar oito cultivares de batata doce da Embrapa: BRS Amélia, Beauregard, Brazlândia Branca, Brazlândia Rosada, Brazlândia Roxa, BRS Cuia, Princesa e BRS Rubissol (MAPA, 2014). As mudas foram provenientes de limpeza clonal, indexadas e multiplicadas em ambiente protegido. O processo de limpeza clonal das mudas dessas cultivares foi realizado segundo a metodologia descrita por Fernandes (2013). As parcelas foram formadas por cinco linhas com cinco plantas, sendo utilizadas como área útil as três plantas centrais das linhas internas perfazendo um total de nove plantas $\left(5,04 \mathrm{~m}^{2}\right)$. Adotou-se o espaçamento de $1,40 \mathrm{~m}$ entre linhas por 0,40 $\mathrm{m}$ entre plantas.

A instalação dos experimentos foi em sucessão a lavouras de milho sem adição de fertilizantes minerais e sem irrigação, em um Latossolo Vermelho-Amarelo distrófico. A análise química de fertilidade dos solos apresentou os seguintes resultados: $\mathrm{pH}\left(\mathrm{H}_{2} \mathrm{O}\right)=$ 5,$5 ; \mathrm{H}^{++}+\mathrm{Al}^{+++}=3,8 \mathrm{cmol} / \mathrm{dm}^{3} ; \mathrm{Ca}^{++}=$ $0,9 \mathrm{cmol}_{\mathrm{c}} / \mathrm{dm}^{3} ; \mathrm{Mg}^{++}=0,6 \mathrm{cmol}_{\mathrm{c}} / \mathrm{dm}^{3}$; $\mathrm{P}($ Mehlich $)=3,6 \mathrm{mg} / \mathrm{dm}^{3} ; \mathrm{K}^{+}=0,19$ $\mathrm{cmol}_{\mathrm{c}} / \mathrm{dm}^{3}$; matéria orgânica $=2,9 \mathrm{~g} /$ $\mathrm{dm}^{3} ; \mathrm{CTC}=5,49 \mathrm{cmol}_{\mathrm{c}} / \mathrm{dm}^{3} ; \mathrm{V}=31 \% \mathrm{e}$ $\mathrm{pH}\left(\mathrm{H}_{2} \mathrm{O}\right)=5,6 ; \mathrm{H}^{++}+\mathrm{Al}^{+++}=4,1 \mathrm{cmol}_{\mathrm{c}} /$ $\mathrm{dm}^{3} ; \mathrm{Ca}^{++}=3,4 \mathrm{cmol} / \mathrm{dm}^{3} ; \mathrm{Mg}^{++}=2,2$ $\mathrm{cmol} / \mathrm{dm}^{3} ; \mathrm{P}($ Mehlich $)=12 \mathrm{mg} / \mathrm{dm}^{3}$; $\mathrm{K}^{+}=0,46 \mathrm{cmol}_{\mathrm{c}} / \mathrm{dm}^{3} ;$ matéria orgânica $=$ $2,8 \mathrm{~g} / \mathrm{dm}^{3} ; \mathrm{CTC}=10,18 \mathrm{cmol}_{\mathrm{c}} / \mathrm{dm}^{3} ; \mathrm{V}=$ $59,7 \%$ respectivamente. A precipitação pluviométrica registrada na estação meteorológica da região na primeira safra foi de $840 \mathrm{~mm}$ e na segunda safra foi de $509 \mathrm{~mm}$ (INMET, 2016).

O preparo do solo foi realizado com uma aração, duas gradagens e a construção de leiras com $85 \mathrm{~cm}$ de largura e 45 $\mathrm{cm}$ de altura. O plantio das mudas foi realizado manualmente com o enterrio da metade da rama. Foi realizada uma capina manual nas linhas de plantio seguida de uma aplicação de Paraquat entre linhas na dosagem de $300 \mathrm{~mL}$ do produto comercial por $100 \mathrm{~L}$ de calda aos 35 dias após o plantio. Aos 153 dias após o plantio foram colhidas e avaliadas as raízes de cada parcela para os caracteres número total de raízes (NTR); número de raízes com padrão comercial (NRC); massa total de raízes (MTR) em t/ha; massa fresca de raízes com padrão comercial (MRC) em t/ha; a massa média de raiz comercial (MMRC) em g/raiz = razão entre MRC e NRC e a porcentagem da MRC em relação à MRT, a massa das raízes foi obtida por meio de pesagem direta em balança eletrônica. Foram consideradas como raízes comerciais aquelas acima de 10 $\mathrm{cm}$ de comprimento e $5 \mathrm{~cm}$ de diâmetro, que não apresentavam tortuosidade, rachadura ou veias muito pronunciadas (Silva et al., 2012).

Foram realizadas ainda as avaliações de formato ("formato") e incidência de danos por insetos de raízes ("insetos") com notas variando de 1 a 5 , conforme Peixoto et al. (1999) e Azevedo et al. (2014). Para "insetos", as notas visuais médias para as raízes da parcela corresponderam a: $1=$ livres de danos por insetos; $2=$ poucos danos; $3=$ danos que prejudicam o aspecto comercial; $4=$ danos que a tornam praticamente imprestável para comercialização; $5=$ danos que a tornam inaceitável para fins comerciais. Para "formato", as notas visuais médias para as raízes da parcela corresponderam a: $1=$ fusiforme regular, sem veias ou rachaduras; $2=$ ligeiramente desuniformes e presença de veias; $3=$ desuniformes, com veias, $\mathrm{e}$ rachaduras grandes; $4=$ muito desuniformes, presença de veias e rachaduras; $5=$ totalmente fora dos padrões comerciais, muito irregular, com veias e rachaduras.

Os dados obtidos foram verificados quanto à distribuição normal dos resíduos pelo teste de Lilliefors e submetidos à análise de variância individual e conjunta para os dois anos, e agrupamento de médias por Skott-Knott a 5\%. Todas as análises estatísticas foram realizadas no programa GENES (Cruz, 2006).

\section{RESULTADOS E DISCUSSÃO}

Pela análise de variância individual para as safras de 2013 e 2014, foram verificadas diferenças significativas, pelo teste $\mathrm{F}$ a $5 \%$ de probabilidade 
$(p<0,05)$, entre as cultivares para todos os caracteres em 2014, enquanto que não houve diferenças significativas para os caracteres massa média de raízes comerciais (MMRC) e incidência de danos por insetos ("insetos") para a safra de 2013.

A análise de variância conjunta demonstrou a existência de interação significativa entre cultivares e safras de cultivo para o número de raízes comerciais (NRC), massa de raízes comerciais (MRC), porcentagem da massa de raízes comerciais em relação à massa total (\%MRC/MRT) e "insetos". Sendo assim, para estes caracteres os resultados foram discutidos em separado para cada safra (Tabela 1). Para os demais caracteres, para os quais não foi verificada interação significativa, o agrupamento de médias foi realizado com os valores médios das duas safras (Tabela 2).

Os coeficientes de variação fenotípicos $(\mathrm{CV})$ para os caracteres relacionados ao rendimento de raízes e que apresentaram interação genótipo $\mathrm{x}$ safra foram maiores em 2013, variando de $26,11 \%$ para NRC a $27,82 \%$ para MRC, e menores em 2014, variando de $9,23 \%$ para $\%$ MRC/MTR a $11,43 \%$ para MRC, indicando que em 2014 as condições ambientais, em especial de solo e clima, possibilitaram maior precisão experimental (Tabela 1). Já para os caracteres que não apresentaram interação, o CV médio para os dois anos variou de $16,73 \%$ MMRC a $29,25 \%$ para massa total de raízes (MTR) (Tabela 2). No entanto, observa-se que estes valores estão de acordo com a literatura e confirmam a informação de que os caracteres relacionados ao rendimento de raiz podem variar conforme o ambiente, por serem estes de herança quantitativa e de forte influência ambiental (Silva et al., 2012). Assim, os coeficientes de variação fenotípicos (CV) para os diferentes caracteres avaliados (Tabelas 1 e 2) foram semelhantes aos diversos trabalhos com a cultura de batata doce encontrados na literatura (Andrade Junior et al., 2012; Barreto et al., 2011; Silva et al., 2012; Azevedo et al., 2014; Massaroto et al., 2014).

Para os caracteres que apresentaram interação genótipo x safra, a relação entre o coeficiente de variação genotípico e fenotípico $(\mathrm{CVg} / \mathrm{CV})$, que indica a superioridade da variação de ordem genotípica em relação à fenotípica e traz maior segurança nas conclusões sobre $o$ desempenho das cultivares, foi superior à unidade para a maioria dos caracteres. Porém, comparando-se com a literatura, podemos concluir que a variabilidade de ordem genética para estes caracteres não é grande entre as cultivares avaliadas, o que é confirmado pela ausência de diferenças significativas pela análise de agrupamento de médias (Tabela 2) (Cavalcante et al., 2009; Borges et al., 2010).

Em relação ao rendimento de raízes comerciais verifica-se que se destacaram positivamente para NRC as cultivares Brazlândia Roxa com 48 raízes em 2013 e 31 em 2014, além das cultivares Beauregard com 32 raízes e BRS Rubissol com 31 raízes em 2014. Para

Tabela 1. Agrupamento de médias para caracteres fenotípicos avaliados em cultivares de batata doce nas safras de 2013 e 2014 na região do Alto Paranaíba-MG (mean grouping of phenotypic characters evaluated in sweet potato cultivars in 2013 and 2014 in Alto Paranaíba region). Brasília, Embrapa Hortaliças, 2013-2014.

\begin{tabular}{lcccc}
\hline \multirow{2}{*}{ Tratamentos } & \multicolumn{3}{c}{$\mathbf{2 0 1 3}$} \\
\cline { 2 - 5 } & NRC & MRC (t/ha) & \%MRC/MRT & Insetos \\
\hline BRS Amélia & $11,25 \mathrm{c}$ & $7,96 \mathrm{~b}$ & $24,09 \mathrm{c}$ & $2,00 \mathrm{a}$ \\
Beauregard & $32,25 \mathrm{~b}$ & $20,69 \mathrm{a}$ & $55,63 \mathrm{a}$ & $1,75 \mathrm{a}$ \\
B. Branca & $32,75 \mathrm{~b}$ & $21,25 \mathrm{a}$ & $38,76 \mathrm{~b}$ & $2,00 \mathrm{a}$ \\
B. Rosada & $14,25 \mathrm{c}$ & $10,00 \mathrm{~b}$ & $30,26 \mathrm{c}$ & $2,00 \mathrm{a}$ \\
B. Roxa & $47,75 \mathrm{a}$ & $24,62 \mathrm{a}$ & $66,31 \mathrm{a}$ & $1,25 \mathrm{a}$ \\
BRS Cuia & $19,25 \mathrm{c}$ & $12,20 \mathrm{~b}$ & $24,90 \mathrm{c}$ & $1,50 \mathrm{a}$ \\
Princesa & $19,50 \mathrm{c}$ & $12,27 \mathrm{~b}$ & $40,56 \mathrm{~b}$ & $2,50 \mathrm{a}$ \\
BRS Rubissol & $19,00 \mathrm{c}$ & $13,80 \mathrm{~b}$ & $42,47 \mathrm{~b}$ & $2,00 \mathrm{a}$ \\
\hline Média & 24,50 & 15,35 & 40,37 & 1,88 \\
CV (\%) & 26,11 & 27,82 & 27,31 & 29,10 \\
CVg/CV & 1,83 & 1,32 & 1,24 & 0,48 \\
\hline & & & $\mathbf{2 0 1 4}$ & \\
\hline BRS Amélia & $23,50 \mathrm{~b}$ & $14,32 \mathrm{a}$ & $61,87 \mathrm{~b}$ & $3,75 \mathrm{a}$ \\
Beauregard & $32,25 \mathrm{a}$ & $17,07 \mathrm{a}$ & $78,04 \mathrm{a}$ & $2,50 \mathrm{~b}$ \\
B. Branca & $24,75 \mathrm{~b}$ & $15,10 \mathrm{a}$ & $57,36 \mathrm{~b}$ & $3,75 \mathrm{a}$ \\
B. Rosada & $28,00 \mathrm{a}$ & $19,20 \mathrm{a}$ & $55,79 \mathrm{~b}$ & $2,50 \mathrm{~b}$ \\
B. Roxa & $30,50 \mathrm{a}$ & $17,33 \mathrm{a}$ & $66,93 \mathrm{~b}$ & $1,50 \mathrm{~b}$ \\
BRS Cuia & $26,00 \mathrm{~b}$ & $15,92 \mathrm{a}$ & $64,21 \mathrm{~b}$ & $3,25 \mathrm{a}$ \\
Princesa & $29,75 \mathrm{a}$ & $17,39 \mathrm{a}$ & $66,50 \mathrm{~b}$ & $2,50 \mathrm{~b}$ \\
BRS Rubissol & $31,00 \mathrm{a}$ & $15,91 \mathrm{a}$ & $74,77 \mathrm{a}$ & $2,00 \mathrm{~b}$ \\
\hline Média & 28,22 & 16,53 & 65,68 & 2,72 \\
CV (\%) & 10,59 & 11,43 & 9,23 & 25,89 \\
CVg/CV & 0,94 & 0,64 & 1,18 & 1,03 \\
\hline NRC=nima & co & & \\
\hline
\end{tabular}

$\mathrm{NRC}=$ número de raízes com padrão comercial por parcela $\left(5,04 \mathrm{~m}^{2}\right)$ (number of roots with commercial standard per plot); $\mathrm{MRC}=$ massa de raízes com padrão comercial (mass of roots with commercial standard); \%MRC/MRT= porcentagem da massa de raízes comerciais em relação à massa total de raízes (percentage of commercial roots mass relative to the root total mass); Insetos (insects) = danos por insetos (insect damage) (notas $1=$ livres de danos por insetos; $2=$ poucos danos; $3=$ danos que prejudicam o aspecto comercial; $4=$ danos que a tornam praticamente imprestável para comercialização; $5=$ danos que a tornam inaceitável para fins comerciais) (scores from $1=$ free of insect damage; $2=$ little damage; $3=$ damage that impair the commercial aspect; $4=$ practically unsuitable for the market; $5=$ completely unsuitable for commercial purposes). Letras iguais na coluna não diferem, Skott-Knott, $5 \%$ (same letters on column do not differ by Skott-Knott test, $5 \%)$. CV $(\%)=$ coeficiente de variação fenotípico (phenotypic coeficient of variation); $\mathrm{CVg} / \mathrm{CV}=$ relação entre o coeficiente de variação genotípico e fenotípico (genotypic and phenotipic coeficient of variation ratio). 
Tabela 2. Agrupamento de médias para caracteres fenotípicos avaliados em cultivares de batata doce na média das safras de 2013 e 2014 na região do Alto Paranaíba-MG (mean grouping of phenotypic characters evaluated on sweet potato cultivars, average value from 2013 and 2014 in Alto Paranaiba region). Brasília, Embrapa, 2014.

\begin{tabular}{lcccc}
\hline Tratamentos & NTR & MTR (t/ha) & MMRC (g/raíz) & Formato \\
\hline BRS Amélia & $52,63 \mathrm{c}$ & $29,89 \mathrm{a}$ & $313,87 \mathrm{a}$ & $3,25 \mathrm{a}$ \\
Beauregard & $75,63 \mathrm{~b}$ & $29,43 \mathrm{a}$ & $273,37 \mathrm{a}$ & $1,63 \mathrm{a}$ \\
B. Branca & $76,75 \mathrm{~b}$ & $40,91 \mathrm{a}$ & $312,10 \mathrm{a}$ & $2,50 \mathrm{a}$ \\
B. Rosada & $44,00 \mathrm{c}$ & $37,05 \mathrm{a}$ & $326,71 \mathrm{a}$ & $2,50 \mathrm{a}$ \\
B. Roxa & $97,13 \mathrm{a}$ & $31,50 \mathrm{a}$ & $253,66 \mathrm{a}$ & $1,13 \mathrm{a}$ \\
BRS Cuia & $56,50 \mathrm{c}$ & $35,40 \mathrm{a}$ & $317,09 \mathrm{a}$ & $3,25 \mathrm{a}$ \\
Princesa & $48,00 \mathrm{c}$ & $28,22 \mathrm{a}$ & $308,37 \mathrm{a}$ & $2,38 \mathrm{a}$ \\
BRS Rubissol & $51,50 \mathrm{c}$ & $26,33 \mathrm{a}$ & $288,33 \mathrm{a}$ & $2,38 \mathrm{a}$ \\
\hline Média & 62,76 & 32,33 & 299,18 & 2,29 \\
CV $(\%)$ & 22,10 & 29,25 & 16,73 & 27,41 \\
CVg/CV & 1,28 & 0,39 & 0,35 & 0,69 \\
\hline
\end{tabular}

$\mathrm{NTR}=$ número total de raízes por parcela $\left(5,04 \mathrm{~m}^{2}\right)$ (total number of roots per plot); MTR: massa total de raízes (total root mass); MMRC: massa média de raízes com padrão comercial (average mass of commercial roots); Índice de formato (shape index) notas $1=$ fusiforme regular, sem veias ou rachaduras; $2=$ ligeiramente desuniformes e presença de veias; $3=$ desuniformes, com veias, rachaduras e grandes; 4= muito desuniformes, presença de veias, rachaduras e grandes; $5=$ totalmente fora dos padrões comerciais, muito irregular, com veias e rachaduras $(1=$ spindle-shaped root, regular, without any veins or cracks; $2=$ root shape considered good, close to fusiform, with some veins; $3=$ roots shaped uneven, with veins and very irregular; $4=$ very large roots, with veins and cracks, commercially undesirable; $5=$ roots completely out of the commercial box, very irregular and deformed, with many veins and cracks). Letra iguais na coluna não diferem, Skott-Knott, 5\% (same letters on column do not differ by Skott-Knott test, $5 \%)$. CV (\%)= coeficiente de variação fenotípico (phenotypic coeficient of variation); $\mathrm{CVg} / \mathrm{CV}=$ relação entre o coeficiente de variação genotípico e fenotípico (genotypic and phenotipic coeficient of variation ratio).

MRC as cultivares Brazlândia Roxa, Brazlândia Branca e Beauregard foram superiores às demais em 2013 com produtividades de 24,62, 21,25 e 20,69 t/ ha, respectivamente. Para \%MRC/MRT a cultivar Beauregard foi mais estável, com elevada porcentagem de raízes comerciais em ambas as safras, $55,63 \%$ em 2013 e 78,04\% em 2014, enquanto que a cv. Brazlândia Roxa apresentou bom desempenho em 2013 (66,31\%) e a BRS Rubissol (74,77\%) agrupou entre as melhores em 2014 (Tabela 1).

Quanto à cultivar Beauregard que se destacou em rendimento de raízes comerciais juntamente com Brazlândia Branca e Brazlândia Roxa em 2013, é importante salientar que a mesma é rica em $\beta$-caroteno e destaca-se pelo elevado potencial produtivo e precocidade, pouco conhecida no mercado nacional, mas é o padrão mais comum em mercados dos Estados Unidos da América do Norte e da Europa, constituindo uma opção respectivamente; esta diferença pode estar associada ao fato de no presente estudo as mudas terem sido submetidas ao cultivo in vitro para limpeza viral. Deve-se considerar ainda que o experimento foi instalado em condições de lavouras comerciais, onde se aproveitou simplesmente resíduos da adubação do milho e não se utilizou irrigação complementar, ou seja, as inovações avaliadas em destaque foram as cultivares e a qualidade das mudas. Além da produtividade apresentada, a cultivar Brazlândia Roxa se destaca ainda por apresentar características qualitativas desejáveis ao mercado da região como casca roxa, formato alongado e polpa creme (Embrapa, 2014).

A cultivar Brazlândia Roxa apresentou também o maior NTR na média das duas safras, com 97,13 raízes/parcela, diferindo estatisticamente do grupo intermediário constituído pelas cultivares Beauregard e Brazlândia Branca, respectivamente com 75,63 e 76,75 raízes/parcela, mas que não diferiram entre si (Tabela 2).

$\mathrm{Na}$ análise conjunta, as cultivares avaliadas não diferiram estatisticamente para a MTR apresentando variação entre 26,33 t/ha para a cultivar BRS Rubissol e 40,91 t/ha para a cultivar Brazlândia Branca (Tabela 2). Estes valores estão coerentes com os observados por outros estudos que também avaliaram genótipos melhorados (Azevedo et al., 2000; Resende, 2000; Andrade Junior et al., 2009, 2012).

Andrade Junior et al. (2009) avaliaram uma das cultivares utilizadas neste estudo, a cultivar Princesa, sem limpeza clonal, colhida aos sete meses após o plantio, e obtiveram MTR de 28,78 t/ha, valor semelhante ao do presente trabalho que foi de $28,22 \mathrm{t} /$ ha na média dos dois anos. Da mesma forma, Mendonça \& Peixoto (1991), com colheita aos 150 dias, verificaram produção total de raízes para Brazlândia Roxa de 20,21 t/ha, valor inferior ao obtido neste trabalho (31,50 t/ha). Resende (2000) avaliou cultivares e épocas de colheita quanto à qualidade e produtividade de raízes, e verificou que aos 150 dias a cultivar Brazlândia Roxa apresentou reduzido rendimento total de raízes $(14,3 \mathrm{t} /$ ha), e concluiu que, para as cultivares 
Brazlândia Roxa e Princesa, seriam necessários ciclos vegetativos acima de 150 dias para haver maior rendimento. Além disto, Resende (1999) verificou que, na média de dois experimentos, o rendimento total de raízes, aos 150 dias, foi de 15,65 t/ha para 'Princesa' e 10,85 t/ha para 'Brazlândia Roxa'; rendimentos também inferiores aos observados no presente trabalho; este autor comenta que, além de um excelente aspecto comercial, 'Brazlândia Roxa' apresenta boa resistência a insetos de solo e ao nematoide das galhas e que um ciclo maior do que 150 dias poderia ser avaliado. Neste sentido, Andrade Junior et al. (2009, 2012), aos sete e seis meses após o plantio, verificaram MTR de 22,38 e 17,10 t/ha para essa cultivar, respectivamente, valores bem inferiores aos do presente estudo, da mesma forma que para a produção comercial. Uma das razões para esta diferença também poderia estar associada ao fato da limpeza das mudas para doenças em laboratório.

Quanto à MMRC todos as cultivares apresentaram desempenhos semelhantes e foram agrupadas conjuntamente na análise das médias; o valor médio foi de 299,18 g/raiz comercial, valor dentro do padrão ideal para o comércio que seria entre 200 a $400 \mathrm{~g}$ de acordo com Miranda (1989). Azevedo et al. (2000) reportaram massa média de tubérculos comerciais variando de 123,3 a 261,4 g para um ciclo de seis meses. Resende (2000), com ciclo de 200 dias, observou MMRC de 387,2 e 381,0 g para as cultivares Brazlândia Roxa e Princesa, respectivamente. Já Andrade Junior et al. (2009), com ciclo de sete meses, verificaram MMRC variando de 182,94 a $320,95 \mathrm{~g}$, e valores de 199,14 e 233,84 g para as cultivares Princesa e Brazlândia Roxa, respectivamente. Na média dos dois anos, no presente estudo, foi verificada massa média de 308,37 e 253,66 g para essas duas cultivares, respectivamente; ou seja, semelhantes aos estudos acima relatados.

Não houve diferença entre as cultivares para o caráter "insetos" em 2013, e todas as cultivares apresentaram notas baixas devido à baixa incidência de danos por insetos naquela safra. Já em 2014 o nível de danos foi suficiente para separar as cultivares em dois grupos, e as cultivares mais resistentes foram Beauregard, Brazlândia Rosada, Princesa, BRS Rubissol e Brazlândia Roxa, esta última com nota 1,50 . Brazlândia Roxa é citada na literatura como cultivar com boa tolerância ao ataque de insetos (Resende, 1999). Azevedo et al. (2014) avaliaram as cultivares Brazlândia Rosada e Princesa e também as classificaram com bom nível de resistência, principalmente a segunda. Peixoto et al. (1999) avaliaram as cultivares Brazlândia Branca e Brazlândia Rosada e consideraram ambas suscetíveis. Barreto et al. (2011) avaliaram as três cultivares 'Brazlândias' e obtiveram resultados concordantes com o presente trabalho, Brazlândia Branca foi suscetível, enquanto Brazlândia Rosada e Brazlândia Roxa foram resistentes, com valor numérico menor para a última. Massaroto et al. (2014) também avaliaram essas três cultivares e obtiveram notas abaixo de 3 para ambas, e Brazlândia Roxa foi a mais resistente.

Não houve diferença estatística para a avaliação de formato. Por outro lado, considerando a safra de 2014 isoladamente, as cultivares BRS Amélia, Brazlândia Branca e BRS Cuia, diferenciaram-se das demais e receberam notas acima de 3,0, indicando formatos menos desejados para o mercado.

Em função das diferentes características avaliadas, as cultivares Brazlândia Roxa e Beauregard e destacam-se em relação às demais para os caracteres de rendimento de raiz nas duas safras avaliadas e nos dois locais. As mesmas também apresentaram formato adequado e boa resistência a insetos, principalmente a Brazlândia Roxa. Os caracteres relacionados ao rendimento de raízes em cultivares de batata doce são bastante influenciados pelo ambiente conforme observado pelos valores do coeficiente de variação ambiental. Não há grande variabilidade genética entre as cultivares avaliadas para os caracteres massa total de raízes, massa média de raízes comerciais e formato de raiz, e para estes caracteres as cultivares apresentaram desempenho semelhante nas duas safras de cultivo. Há de se destacar ainda que a cultivar Brazlândia Roxa possui características qualitativas desejáveis ao mercado da região por possuir formato alongado, polpa creme e casca roxa.

\section{REFERÊNCIAS}

AMARO, GB; CARMONA, PAO; FERNANDES, FR; SILVA, GO; PEIXOTO, JR. 2014. Desempenho de cultivares de batata doce a partir de mudas de alta qualidade fitossanitária em Ceilândia-DF. Horticultura Brasileira 31: S2003-S2010.

ANDRADE JUNIOR, VC; VIANA, DJS; FERNANDES, JSC; FIGUEIREDO, JA; NUNES, UR; NEIVA, IP. 2009. Selection of sweet potato clones for the region Alto Vale do Jequitinhonha. Horticultura Brasileira 27: 389-393.

ANDRADE JÚNIOR, VC; VIANA, DJS; PINTO, NAVD; RIBEIRO, KG; PEREIRA, RC; NEIVA, IP; AZEVEDO, AM; ANDRADE, PCR. 2012. Características produtivas e qualitativas de ramas e raízes de batata doce. Horticultura Brasileira 30: 584-589.

AZEVEDO, AM; ANDRADE JÚNIOR, VC; VIANA, DJS; ELSAYED, AYAM; PEDROSA, CE; NEIVA, IP; FIGUEIREDO, JA. 2014. Influence of harvest time and cultivation sites on the productivity and quality of sweet potato. Horticultura Brasileira 32: 21-27.

AZEVEDO, SM; FREITAS, JA; MALUF, WR; SILVEIRA, MA. 2000. Desempenho de clones e métodos de plantio de batata doce. Acta Scientiarum 22: 901-905.

BARRETO, HG; SANTOS, LB; OLIVEIRA, GIS SANTOS, GR; FIDELIS, RR; SILVEIRA, MA; NASCIMENTO, IR. 2011. Estabilidade e adaptabilidade da produtividade e da reação a insetos de solo em genótipos experimentais e comerciais de batata doce. Bioscience Journal 27: 739-747.

BORGES, V; FERREIRA, PV; SOARES, L; SANTOS, GM; SANTOS, AMM. 2010. Seleção de clones de batata doce pelo procedimento REML/BLUP. Acta Scientiarum 32: 643-649.

CAVALCANTE, M; FERREIRA, PV; PAIXÃO, SL; COSTA, JG; PEREIRA, RG; MADALENA JAS. 2009. Potenciais produtivo e genético de clones de batata doce. Acta Scientiarum 31: 421-426.

CRUZ, CD. 2006. Programa Genes: biometria: UFV. 382p.

EMBRAPA, 2014. Cultivares da Embrapa Hortaliças (1981-2013). Brasília, DF: Embrapa, 2014. 182p. Disponível em: http:// ainfo.cnptia.embrapa.br/digital/bitstream/ item/105302/1/Portifolio27-dez.pdf. Acessado em 11 de abril de 2016.

FERNANDES, FR. 2013. Limpeza clonal de batata doce: produção de matrizes com elevada qualidade fitossanitária. Brasília:Embrapa Hortaliças. 8p.

IBGE - Instituto Brasileiro de Geografia e Estatística. 2014. Tabela 1612 - Área plantada, área colhida, quantidade produzida e valor da produção da lavoura temporária. Rio de Janeiro: IBGE. Disponível em: <http:// www.sidra.ibge.gov.br/bda/tabela/listabl. asp? $c=1612 \& z=p \& o=27>$. Acessado em 20 
de junho de 2014.

INMET - Instituto Nacional de Meteorologia. 2016. Rede de estações, Estações automáticas, Gráficos. Brasília: INMET. Disponível em: $<$ http://www.inmet.gov.br/portal/index. $\mathrm{php} ? \mathrm{r}=$ home/page\&page $=$ rede_estacoes auto_graf $>$. Acessado em 28 de março de 2016.

MAPA. 2014. Cultivares de batata doce registradas. Brasília. Disponível em: $<$ http://extranet.agricultura.gov.br/php/snpc/ cultivarweb/cultivares_registradas.php $>$. Acessado em 08 de agosto de 2014.

MASSAROTO JA; MALUF, WR; GOMES, LAA; FRANCO, HD; GASPARINO, CF. 2014. Desempenho de clones de batata doce. Ambiência 10: 73-81.

MENDONÇA, ATC; PEIXOTO, N. 1991. Efeito do espaçamento e de níveis de adubação em cultivares de batata doce. Horticultura Brasileira 9: 80-82.

MIRANDA, JEC. 1989. Brazlândia Roxa; Brazlândia Branca; Brazlândia Rosada e Coquinho: novas cultivares de batata doce. Horticultura Brasileira 7: 32-33.

PEIXOTO, JR; SANTOS, LC; RODRIGUES, FA; JULIATTI, FC; LYRA, JRM. 1999. Seleção de clones de batata doce resistentes a insetos de solo. Pesquisa Agropecuária Brasileira 34: 385-389.

RESENDE, GM. 1999. Características produtivas de cultivares de batata doce sob condições irrigadas e de sequeiro na região norte de Minas Gerais. Horticultura Brasileira 17: 151-154.
RESENDE, GM. 2000. Características produtivas de cultivares de batata doce em duas épocas de colheita; em Porteirinha-MG. Horticultura Brasileira 18: 68-71.

RITSCHEL, PS; HUAMÁN, Z. 2002. Variabilidade morfológica da coleção de germoplasma de batata doce da Embrapa Hortaliças. Pesquisa Agropecuária Brasileira 37: 485-492.

SCHULTHEIS, JR; WALTERS, SA; ADAMS, DE; ESTES, EA. 1999. In row plant spacing and date of harvest of 'Beauregard' sweetpotato affect yield and return on investment. HortScience 34: 1229-1233.

SILVA GO; PONIJALEKI, R; SUINAGA, FA. 2012. Divergência genética entre acessos de batata doce utilizando caracteres fenotípicos de raiz. Horticultura Brasileira 30: 595-599. 